Recebido em 08/2015. Aceito para publicação em 06/2018.

\title{
AVALIAÇÃO QUALITATIVA DAS PREPARAÇÕES DO CARDÁPIO DE ALMOÇO DOS FUNCIONÁRIOS DE UMA ASSOCIAÇÃO PARA DEFICIENTES EM SÃO PAULO
}

\section{QUALITATIVE ASSESSMENT OF THE LUNCH MENU PREPARATIONS FOR THE EMPLOYEES OF AN ASSOCIATION FOR DISABLED IN SÃO PAULO}

\author{
Aline Veroneze de Mello ${ }^{1}$ \\ Juliana Masami Morimoto²
}

Resumo: Avaliar a qualidade do cardápio de almoço dos funcionários de uma associação para deficientes em São Paulo e comparar com os parâmetros preconizados pelo Programa de Alimentação do Trabalhador (PAT). Material e Métodos: Foi utilizado o método AQPC (Avaliação qualitativa das preparações do cardápio), para avaliar o cardápio da Unidade de Alimentação e Nutrição (UAN), seguindo os seguintes critérios: presença de frutas, doces e frituras ou sua associação, carnes gordurosas, oferta de folhosos, presença de alimentos ricos em enxofre e combinação de cores. Resultados: Os clientes da UAN têm preferência por sobremesas elaboradas, que estão incluídas no cardápio todos os dias e, em $69 \%$ deles há frutas como opção ao doce. Frituras estão presentes em $45,2 \%$ dos dias e a associação de doces e frituras apresenta-se em $42,9 \%$ das vezes; carne gordurosa foi ofertada em $54,8 \%$ dos dias, a oferta de folhosos teve $100 \%$ de ocorrência, e em $42,9 \%$ dos dias o feijão estava associado a duas ou mais preparações ricas em enxofre. Obteve-se um valor de 16,7\% de NDPCal\% (Net Dietary Protein Calories - \%). Conclusão: Embora a UAN apresente um cardápio que oferte folhosos diariamente, também fornece uma elevada quantidade de doces, frituras, carnes gordurosas e NDPCal\%, além de não apresentar frutas no cardápio em todos os dias, o que o torna inadequado em relação à legislação do PAT. Ainda, é importante que os cardápios contenham preparações coloridas. Contudo, o método AQPC pode ser um bom instrumento de planejamento de cardápios mais atrativos, variados e saudáveis.

Palavras-chave: Alimentos; planejamento de cardápio; unidade de alimentação e nutrição; análise qualitativa.

Abstract: To evaluate the quality of the lunch menu of employees of an association for disabled in São Paulo and compare it with the parameters recommended by the "Programa de Alimentação do Trabalhador" (PAT). Material and Methods: The AQPC method was used to evaluate the menu of the "Unidade de Alimentação e Nutrição" (UAN) following the criteria: presence of fruits, sweets and fried foods or their association, fatty meats, offer of leafy vegetables, the presence of sulfur-rich foods and the combination of colors. Results: UAN customers prefer elaborate desserts, which are included in the menu every day and in $69 \%$ of them, there are fruits as an option to sweets. Fried foods are present in $45.2 \%$ of the days and the association of sweets and fried foods is present in $42.9 \%$ of the times; fatty meat has been offered in $54.8 \%$ of the days, the supply of leafy vegetables had $100 \%$ of occurrence and in $42.9 \%$ of the days, beans were associated with two or more sulfur-rich preparations. NDPCal\% (Net Dietary Protein Calories $-\%$ ) was 16.7\%. Conclusion: Although UAN presents a menu that offers leafy vegetables daily, it also provides a high amount of sweets, fried foods, fatty meats and NDPCal\%, and does not present fruits on the menu every day, which makes it inappropriate in relation to PAT legislation. In addition, it is important that the menus

\footnotetext{
${ }^{1}$ Nutricionista, Universidade Presbiteriana Mackenzie, Brasil. E-mail: alinevm3@hotmail.com.

2 Docente do curso de Nutrição da Universidade Presbiteriana Mackenzie, Brasil. E-mail: juliana.morimoto@mackenzie.br.

Revista Univap - revista.univap.br

São José dos Campos-SP-Brasil, v. 24, n. 46, dez. 2018. ISSN 2237-1753
} 
contain colored preparations. In this way, the AQPC method can be a good tool for more attractive, varied and healthy menu planning.

Keywords: Foods; menu planning; unit of food and nutrition; qualitative analysis.

\section{INTRODUÇÃO}

A alimentação é uma das atividades mais importantes do ser humano, tanto por razões biológicas quanto por questões sociais e culturais que envolvem o ato de comer. Diversos fatores influenciam a alimentação e, estes vão desde a produção dos alimentos até a sua transformação em refeições e disponibilidade para o consumo (PROENÇA, 2010).

Os gastos com a alimentação fora do domicílio representam $21 \%$ do total dos gastos com refeições, tendo importante participação na dieta dos brasileiros. A alimentação fora do domicílio está relacionada ao excesso de peso e obesidade entre homens adultos no Brasil, uma vez que as escolhas alimentares são, geralmente, por alimentos que possuem maiores quantidades de energia, gorduras totais e saturadas, quando comparadas às refeições preparadas no lar (CANELLA; BANDONI; JAIME, 2011).

No contexto da alimentação fora de casa, para a melhoria das condições nutricionais, principalmente dos trabalhadores de baixa renda (aqueles com menos de cinco salários mínimos), em 1976, foi instituído pela Lei 6.321 o Programa de Alimentação do Trabalhador (PAT), com destaque para melhoria da capacidade e da resistência física dos trabalhadores, redução da mortalidade e de doenças relacionadas a hábitos alimentares, maior integração entre trabalhador e empresa, com consequente redução das faltas, rotatividade, aumento na produtividade e melhor qualidade dos serviços (BRASIL, 2014).

As Unidades de Alimentação e Nutrição (UANs) têm por objetivo fornecer refeições equilibradas e saudáveis para funcionários de empresas, complexos industriais, escolas, instituições filantrópicas, entre outras (ABREU; SPINELLI; PINTO, 2011). Dessa maneira, para proporcionar refeições de qualidade, o gerenciamento e a administração da UAN devem ser feitos pelo nutricionista, que tem como função planejar, organizar, dirigir, supervisionar e avaliar todas as etapas do sistema de alimentação que compõem o processo produtivo (CFN, 2005).

De acordo com a Organização Mundial da Saúde (WHO, 2004), o local de trabalho tem que dar a oportunidade e encorajar hábitos saudáveis de alimentação aos trabalhadores para reduzir sua exposição a riscos de saúde e prevenir doenças. A alimentação dos trabalhadores, no ambiente de trabalho, pode aumentar em 10\% a produtividade, reduzir o risco de doenças e acidentes de trabalho (CARNEIRO; MOURA; SOUZA, 2013). 
No contexto da alimentação na empresa, o cardápio é um instrumento fundamental e contínuo elaborado pelo nutricionista que deve garantir a oferta mínima de energia e nutrientes, promover hábitos alimentares saudáveis, proporcionar uma refeição de acordo com o público-alvo, além de conciliar os custos. O planejamento auxilia no dimensionamento dos recursos humanos e materiais, no controle de custos, no pedido de compras, na fixação dos níveis de estoque, na determinação dos padrões a serem utilizados para confecção das receitas, contemplando ainda a pesquisa e análise das preferências alimentares dos clientes (SILVA; MARTINEZ, 2008). Contudo, o planejamento inadequado interfere na qualidade da alimentação oferecida, resultando em preparações monótonas, desequilibradas nutricionalmente e pouco atrativas (BRITO; BEZERRA, 2013).

Diante do exposto, o método de Análise Qualitativa das Preparações do Cardápio (AQPC) foi criado visando a auxiliar o profissional na elaboração adequada do cardápio pelo aspecto nutricional e sensorial dentro dos parâmetros de saúde, devendo ser qualitativa e quantitativamente adequados ao hábito alimentar e capazes de promover uma vida saudável, que previna o aparecimento de doenças. O método propõe a avaliação de cores, técnicas de preparo, repetições, combinações, oferta de folhosos, frutas e sucos de frutas, tipos de carnes e o teor de enxofre dos alimentos (PROENÇA et al., 2005). Com a aplicação do método, há parâmetros para a avaliação global do cardápio. É importante ressaltar que se trata de um instrumento que não foi validado, mas serve e é amplamente utilizado como ferramenta qualitativa que norteia uma avaliação geral dos aspectos nutricionais e sensoriais que compõem um cardápio.

Assim, o presente estudo teve como finalidade avaliar a qualidade quanto aos aspectos de combinação na disposição dos alimentos ou grupos alimentares e nutricionais do cardápio de almoço dos funcionários de uma associação para deficientes em São Paulo, bem como comparar esses aspectos com as recomendações preconizadas pelo PAT.

\section{MATERIAL E MÉTODOS}

Trata-se de um estudo de delineamento transversal, no qual foram avaliados cardápios de uma UAN hospitalar de uma associação para deficientes em São Paulo Capital. Foram analisados cardápios de almoço de domingo a sábado, durante seis semanas, totalizando 42 dias. Não foram incluídos cardápios dos pacientes da unidade hospitalar, somente aqueles destinados aos funcionários da UAN.

Para análise, foi utilizado o método AQPC desenvolvido por Veiros (2002) e Proença et al. (2008), compreendendo 4 passos (adaptados a UAN): 
- $1^{\circ}$ passo: foram estabelecidos para cada cardápio os itens a serem avaliados por dia, posteriormente por semanas, considerando os cardápios da UAN;

- $\quad 2^{\circ}$ passo: foram definidos os critérios estabelecidos para escolha dos itens de avaliação da AQPC:

- presença de frituras, de maneira isolada e, também, associada aos doces, levando ao risco do elevado consumo de alimentos preparados com essa técnica de cocção e, também, a associação do excesso lipídico aos carboidratos simples;

- cor das preparações e alimentos empregados no cardápio, apontando a combinação de cores da composição do prato, alertando para a importância do aspecto visual da alimentação (quando pelo menos $50 \%$ dos alimentos apresentaram cores semelhantes ou iguais) (MENEGAZZO, 2011);

- presença de alimentos ricos em enxofre (oferta de duas ou mais preparações, excluindo o feijão, dos seguintes alimentos sulfurados: abacate, acelga, aipo, alho, amendoim, batata-doce, brócolis, castanha, cebola, couve-debruxelas, couve-flor, ervilha, gengibre, goiaba, jaca, lentilha, maçã, melancia, melão, milho, mostarda, nabo, nozes, ovo, rabanete, repolho e uva);

- presença de itens importantes no cardápio, componentes de uma alimentação nutricionalmente adequada, como frutas e folhosos, pela oferta de vitaminas, minerais e fibras;

- presença de carne gordurosa nos dias em que não há emprego da fritura, como técnica de preparo nas carnes oferecidas (com teor de gordura acima de $50 \%$ do valor energético total (VET), tais como, picanha, fraldinha, acém, capa de filé, costela, contrafilé, paleta, pescoço, ponta de agulha e vísceras) (PHILIPPI, 2003) e a oferta de doces como sobremesa.

- $3^{\circ}$ passo: foram distribuídos os cardápios diariamente e, logo após, semanalmente, por meio da avaliação da oferta ou não desses alimentos e preparações e destrinchados, de acordo com os seguintes grupos de alimentos que compõem o instrumento:

- Presença de frutas ou sucos de frutas;

- Oferta de folhosos;

- Alimentos ricos em enxofre;

- Presença de frituras, presença de doces, bem como sua associação;

- Carnes gordurosas; 
- Monotonia de cores.

- $\quad 4^{\circ}$ passo: Os dados foram tabulados no programa Microsoft Excelß 2010 e apresentados em números, de acordo com as semanas e percentuais de ocorrência.

O responsável pela UAN autorizou a utilização dos cardápios para análise qualitativa, por meio do Termo de Consentimento Livre e Esclarecido à Instituição.

\section{RESULTADOS E DISCUSSÃO}

A UAN estudada atende os funcionários da instituição e fornece cerca de 700 refeições diárias (de segunda a sexta feira), 160 refeições aos sábados e 130 refeições aos domingos. O cardápio é elaborado trimestralmente e o sistema de distribuição das refeições é do tipo self-service, com exceção do prato principal e da guarnição que são porcionados.

O cardápio da UAN é composto por arroz, feijão, três tipos de saladas, uma guarnição, um prato principal e duas opções ao prato principal (uma é sempre ovo e a outra varia entre peixe, frango ou carne vermelha), doce como sobremesa ou outra opção (podendo ser fruta ou outro tipo de doce) e suco industrializado de máquina.

Os dados resultantes da avaliação dos 42 cardápios de seis semanas pelo método AQPC estão representados na Tabela 1.

Tabela 1 - Distribuição em número e percentual da ocorrência de alimentos e preparações dos cardápios da UAN, segundo método AQPC. São Paulo, 2015.

\begin{tabular}{cccccccccc}
\hline Semanas & Dias & Frutas & Doce & Frituras & $\begin{array}{c}\text { Doce }+ \\
\text { fritura }\end{array}$ & $\begin{array}{c}\text { Carne } \\
\text { Gordurosa }\end{array}$ & Folhosos & $\begin{array}{c}\text { Cores } \\
\text { iguais }\end{array}$ & $\begin{array}{c}\text { Ricos em } \\
\text { enxofre }\end{array}$ \\
\hline 1 & 7 & 4 & 7 & 3 & 3 & 4 & 7 & 2 & 2 \\
2 & 7 & 6 & 7 & 4 & 4 & 5 & 7 & 0 & 3 \\
3 & 7 & 4 & 7 & 4 & 4 & 3 & 7 & 2 & 2 \\
4 & 7 & 6 & 7 & 3 & 3 & 5 & 7 & 6 & 4 \\
5 & 7 & 4 & 7 & 3 & 3 & 4 & 7 & 4 & 4 \\
6 & 7 & 5 & 7 & 2 & 2 & 2 & 7 & 3 & 3 \\
\hline $\begin{array}{c}\text { Total de } \\
\text { dias }\end{array}$ & 42 & 29 & 42 & 19 & 19 & 23 & 42 & 17 & 18 \\
\hline $\begin{array}{c}\% \text { de } \\
\text { ocorrência }\end{array}$ & & 69,0 & 100,0 & 45,2 & 45,2 & 54,8 & 100,0 & 40,5 & 42,9 \\
\hline
\end{tabular}

O cardápio ofertado fornece folhosos diariamente, o que atende à determinação da legislação do PAT sobre a obrigatoriedade da presença de legumes ou verduras nas refeições principais diariamente. Já as frutas tiveram $69 \%$ de ocorrência, o que não 
atende a legislação que define a obrigatoriedade da presença diária de frutas nas refeições principais. Há doces todos os dias, frituras em menos de $50 \%$ dos dias avaliados e carnes gordurosas acima de $50 \%$ de ocorrência, o que pode elevar o teor de gorduras do cardápio, tornando-o inadequado em relação à legislação (Tabela 1).

Os clientes da UAN têm preferência por sobremesas elaboradas, como pudim, sagu, gelatina, creme de chocolate, curau, manjar, entre outros. Dessa forma, doces são incluídos no cardápio todos os dias e em $69 \%$ dos dias há frutas como opção ao doce. Veiros e Proença (2003) encontraram preferências semelhantes na UAN que estudaram, com frequência de oferta de $66,1 \%$. A Associação Brasileira para Estudo da Obesidade e da Síndrome Metabólica (ABESO) indica que o consumo elevado de doces e redução no consumo de frutas pode contribuir para ocorrência de obesidade e outras doenças associadas (ABESO, 2014).

A oferta de frutas ocorreu em $69 \%$ dos dias. Apesar de ser um percentual alto, percebe-se que os trabalhadores consomem doces todos os dias. Sabe-se que o consumo insuficiente de frutas está entre os dez principais fatores de risco para a carga total global de doenças crônicas não transmissíveis (DCNT) em todo o mundo. É importante ressaltar que o consumo de frutas deve fazer parte de uma dieta saudável, pois são fontes de vitaminas, sais minerais, fibras, substâncias antioxidantes e de outros compostos com propriedades funcionais (FIGUEIREDO; JAIME; MONTEIRO, 2008). Além disso, o PAT preconiza que os cardápios deverão oferecer, pelo menos, uma porção de frutas e uma porção de legumes ou verduras, nas refeições principais: almoço, jantar e ceia (BRASIL, 2006).

As frituras estão presentes em $45,2 \%$ dos dias, fato que pode ser explicado pela presença diária da opção de ovos no cardápio e pelas técnicas de preparo, que, geralmente, são: omelete com legumes ou salsa, ovos fritos, ovos mexidos e ovos pochê, associados às preparações de prato principal, como filés de frango ou peixe à milanesa, croquetes e outras preparações fritas, incluídas no cardápio. A quantidade excessiva de alimentos fritos pode representar riscos à saúde, em decorrência da possibilidade de formação de produtos tóxicos durante o processo de fritura, no qual poderão ocorrer modificações (funcionais, sensoriais e nutricionais) no óleo, podendo chegar a níveis em que não se consegue mais obter alimentos de boa qualidade (DEL RÉ; JORGE, 2006).

A associação de doces com fritura está presente em $42,9 \%$ dos dias. O consumo frequente de alimentos com alta concentração calórica, ricos em gorduras e/ou açúcares, tem sido considerado, atualmente, importante fator para o aumento da prevalência de diversas DCNT (ZANINI et al., 2013).

A oferta de carne gordurosa ocorreu em 54,8\% dos dias. Tal resultado apresentou-se elevado em relação ao resultado de $37,5 \%$, obtido no estudo de Passos (2008) que utilizou o método AQPC para preparações do cardápio de uma UAN 
institucional em Brasília. O estudo considerou os seguintes tipos de carnes como gordurosas, baseando-se na Tabela Brasileira de Composição de Alimentos (TACO): carne seca, linguiça, calabresa, bacon, carnes salgadas, lombo de porco, pernil, coxa e sobrecoxa com pele e o presente estudo os seguintes tipos, baseando-se no livro "Nutrição e técnica dietética" (PHILIPPI, 2003): acém, contrafilé, capa de filé, costela, linguiça, coxa e sobrecoxa com pele e lombo.

O PAT preconiza um valor para o NDPCal\% - Net Dietary Protein Calories (\%). O NDPCal\% estima a quantidade de proteínas líquidas da refeição, ou seja, a quantidade que será, realmente, utilizada pelo organismo. Ao realizar uma média dos valores dos cardápios (cálculo teórico e não o consumo real dos funcionários) obteve-se um valor de $16,7 \%$, que se encontra acima do parâmetro estabelecido como adequado (mínimo, 6\%; e, no máximo, 10\%) (BRASIL, 2006).

A carne é um item que deve estar presente em uma dieta equilibrada, porém o consumo elevado tem sido apontado como um fator preocupante. As carnes, especialmente as vermelhas e processadas, contêm grande concentração de colesterol, ácidos graxos saturados e sódio, substâncias associadas à incidência de doenças cardiovasculares (SCHNEIDER; DURO; ASSUNÇÃO, 2014).

A oferta de folhosos foi encontrada em todos os dias de análise. Resultado semelhante foi encontrado por Prado, Nicoletti e Faria (2013), no qual identificaram a oferta de folhosos em $100 \%$ dos dias, em uma UAN da cidade de Cuiabá, durante o período de 20 dias. A grande importância do consumo de hortaliças e folhosas variadas na dieta deve-se ao seu efeito alcalinizante sistêmico, composição rica em vitaminas e sais minerais e aumento do resíduo alimentar para compor o bolo fecal, no trato digestório (ORNELLAS, 2007).

Preparações e/ou alimentos com cores iguais representam 40,5\% das ocorrências. Em estudo realizado por Longo-Silva et al. (2013), em creches públicas do município de São Paulo, encontraram-se 35,7\% de repetições de cores, o que se mostra semelhante ao presente estudo. De acordo com o Guia Alimentar para População Brasileira, um dos principais atributos para uma alimentação saudável é que a refeição seja naturalmente colorida (BRASIL, 2006).

Não há definição sobre alimentos ricos em enxofre na legislação do PAT, porém apesar de existirem outros fatores, esses alimentos podem ser causadores de desconforto abdominal e gases, pela presença de componentes sulfurados, e, portanto, estudos sugerem evitar o consumo concomitante de mais de duas preparações e/ou alimentos que contenham enxofre (SUAREZ; SPRINGFIELD; LEVITT, 1988; PROENÇA, 2005). Na UAN estudada, em $42,9 \%$ dos dias o feijão estava associado a duas ou mais preparações ricas em enxofre.

O presente estudo apresenta limitações. Primeiramente, a oferta de alimentos foi avaliada em cardápio de 42 dias, e este pode variar sazonalmente, de acordo com a 
disponibilidade de alimentos. Ainda, podem ter ocorrido possíveis substituições de alimentos, em relação ao cardápio previsto, que não foram avaliadas no presente estudo.

\section{CONCLUSÃO}

Por fim, conclui-se que, embora a UAN apresente um cardápio que oferte folhosos diariamente, também fornece uma elevada quantidade de doces, frituras, carnes gordurosas e NDPCal\%, além de não apresentar frutas no cardápio em todos os dias, o que o torna inadequado em relação à legislação do PAT. Além disso, é importante que os cardápios contenham preparações coloridas que são mais completas nutricionalmente, uma vez que, quando as cores são variadas, há também uma variação das vitaminas e sais minerais contidos nos cardápios. Dessa maneira, o método AQPC pode ser um bom instrumento ao nutricionista para planejar um cardápio adequado e auxiliar para que estes sejam mais atrativos, coloridos, variados e saudáveis.

\section{REFERÊNCIAS}

ABESO. É Melhor Prevenir: Dicas de prevenção da obesidade. Disponível em: <http://www.abeso.org.br/lenoticia/542/e+melhor+prevenir.shtml>. Acesso em: 14 de nov. 2014.

ABREU, E.S; SPINELLI, M.G.N.; PINTO, A.M. Gestão de unidades de alimentação e nutrição: um modo de fazer. 4. ed. São Paulo: Metha; 2011.

BRASIL. Ministério do Trabalho e Emprego. Portaria Interministerial $n^{\circ} 66$, de 25 de agosto de 2006. Altera os parâmetros nutricionais do Programa de Alimentação do Trabalhador - PAT . Diário Oficial da União, 2006. Disponível em: <http://189.28.128.100/nutricao/docs/legislacao/portaria66_25_08_06.pdf>. Acesso em: 10 nov. 2014.

BRITO, L.F; BEZERRA, V.M. Avaliação qualitativa das preparações do cardápio de uma unidade de alimentação e nutrição hospitalar de vitória da conquista, Bahia. Alim. Nutr., v. 24, n. 2, p. 153-158, 2013.

CANELLA, D.S.; BANDONI, D.H.; JAIME, P.C. Densidade energética de refeições oferecidas em empresas inscritas no programa de alimentação do Trabalhador no município de São Paulo. Rev. Nutr., v. 24, n. 5, p. 715-724, 2011.

CARNEIRO, N.S.; MOURA, C.M.A.; SOUZA, S.C.C. Avaliação do almoço servido em uma unidade de alimentação e nutrição, segundo os critérios do programa de alimentação do trabalhador. Alim. Nutr., v. 24, n. 3, p. 361-365, 2013.

CFN. Resolução RDC ํ380, de janeiro de 2005. Dispõe sobre a definição das áreas de atuação do Nutricionista e suas atribuições, estabelece parâmetros numéricos de 
referência por área de atuação e dá outras providências. Diário Oficial da União; Poder Executivo, de 10 janeiro de 2006.

DEL RÉ, P. V.; JORGE, N. Comportamento de óleos vegetais em frituras descontínuas de produtos pré-fritos congelados. Ciênc. Tecnol. Aliment., v. 26, n. 1, p. 56-63, 2006.

FIGUEIREDO, I. C. R.; JAIME, P. C.; MONTEIRO, C. A. Fatores associados ao consumo de frutas, legumes e verduras em adultos da cidade de São Paulo. Rev Saúde Pública, v. 42, n. 5, p. 777-85, 2008.

LONGO-SILVA, G. et al. Qualitative evaluation of the menu and plate waste in public day care centers in São Paulo city, Brazil. Rev. Nutr., v. 26, n. 2, p.135-144, 2013.

MENEGAZZO, M. et al. Avaliação qualitativa das preparações do cardápio de centros de educação infantil. Rev Nutr, v. 24, n. 2, p. 243-251, 2011.

ORNELLAS, L. H. Técnica dietética: seleção e preparo dos alimentos. 8. ed. São Paulo: Atheneu, 2007. 276p.

PASSOS, A. L. A. Análise do cardápio de uma unidade de institucional em Brasília - DF segundo o "Método de avaliação qualitativa das preparações do cardápio". 2008. Monografia (Especialização) - Universidade de Brasília, Brasília, 2008.

PHILIPPI, S.T. Nutrição e técnica dietética. 2 ed. Barueri: Manole, 2003.

PRADO, B.G; NICOLETTI, A. L.; FARIA, C. S. Avaliação Qualitativa das Preparações de Cardápio em uma Unidade de Alimentação e Nutrição de Cuiabá- MT. UNOPAR Cient. Ciênc.Biol. Saúde, v. 15, n. 3, p. 219-23, 2013.

PROENÇA, R.P.C. Alimentação e globalização: algumas reflexões. Cienc. Cult., São Paulo, v. 62, n. 4, 2010.

PROENÇA, R.P.C. et al. Qualidade nutricional e sensorial na produção de refeições. Florianópolis: Editora da UFSC, 2005.

PROENÇA, R.P.C. et al. Qualidade nutricional e sensorial na produção de refeições. Florianópolis: Editora da UFSC, 2008. 221p.

SCHNEIDER, B. C.; DURO, S. M. S.; ASSUNÇÃO, M. C. F. Consumo de carnes por adultos do sul do Brasil: um estudo de base populacional. Ciência \& Saúde Coletiva, v. 19 , n. 8, p. 3583-3592, 2014.

SILVA, S.M.C.S.; MARTINEZ, S. Cardápio: guia prático para elaboração. 2. ed. São Paulo: Atheneu, 2008.

SUAREZ, F.L.; SPRINGFIELD, J.; LEVITT, M.D. Identification of gases responsible for the odour of human flatus and evaluation of a device purported to reduce this odour. Gut, v.43, p.100-104, 1988.

VEIROS, M.B. Análise das condições de trabalho do nutricionista na atuação como promotor de saúde em uma unidade de alimentação e nutrição: um estudo de caso. Dissertação (Mestrado) - Universidade Federal de Santa Catarina, Florianópolis, 2002. 
VEIROS, M.B.; PROENÇA, R.P.D.C. Avaliação qualitativa das preparações do cardápio em uma unidade de alimentação e nutrição - Método AQPC. Nutr. Pauta, v. 11, n. 62, p. 36-42, 2003.

WHO. World Health Organization. Global strategy on diet, physical activity and health, 2004. Food Nutr. Bull., v.25, n.3, p.292-302, 2004.

ZANINI, R. V., et al. Consumo diário de refrigerantes, doces e frituras em adolescentes do Nordeste brasileiro. Ciênc. Saúde Coletiva, v. 18, n. 12, p. 3739-3750, 2013. 